\title{
CARACTERIZAÇÃO QUÍMICA E FÍSICA DE TURFA LITORÂNEA E AVALIAÇÃo DA ADSORÇÃo COMPETITIVA POR COBRE E ZINCO
}

\author{
Agenor Paulo Binato Lamim \\ Departamento de Química, Universidade Federal de Juiz de Fora, 36100-000 Juiz de Fora - MG \\ Cláudio Pereira Jordão, José Luis Pereira e Carlos Roberto Bellato \\ Departamento de Química, Universidade Federal de Viçosa, 36571-000 Viçosa - MG
}

Recebido em 13/10/99; aceito em 27/9/00

\begin{abstract}
CHEMICAL AND PHYSICAL CHARACTERIZATION OF COASTAL PEAT AND EVALUATION OF COMPETITIVE ADSORPTION OF COPPER AND ZINC. The chemical and physical characterization of coastal peat has been studied. It was examined the $\mathrm{pH}$, organic matter content and elementary and XRD analyses, among other characteristics. The peat was then applied to the retention and competition of metal micronutrients $(\mathrm{Cu}$ and $\mathrm{Zn})$ from metal nitrate solutions. The retention was affected by both the $\mathrm{pH}$ and time of adsorption, while the competitive character of these metals for the substrate was relevant to each $\mathrm{pH}$ examined.
\end{abstract}

Keywords: heavy metals; coastal peat; copper and zinc competition.

\section{INTRODUÇÃO}

A formação das turfeiras tem por origem a sedimentação da areia, limo e argila oriundas dos terrenos à montante, a deposição de vegetais que crescem emergindo ou sobrenadando na água e a contribuição das plantas existentes nas bordas da região alagada. Estima-se que são necessários de 100 a 500 anos para produzir uma camada de 30 centímetros de turfa. As turfas brasileiras podem ser classificadas como hídrica, fibrosa e lenhosa. A primeira é formada em ambiente aquoso ou subaquoso, produzindo uma espécie de turfa rudimentar à base de algas, pólens, plânctons e flora aquática. A segunda, comum na região Sudeste do Brasil, ocorre na superfície de terrenos, originada por acúmulos orgânicos naturais ou plantados pelo homem, compondo-se de fibras e filamentos pouco decompostos, imersos em matriz de aspecto gelatinoso, de coloração escura ou marron. A terceira, é formada por vegetais de grande porte e originada na superfície de terreno. Grande parte da matéria orgânica da turfa está humificada, mas ainda consiste de um material suscetível de fermentar e tornar-se estabilizado ${ }^{1}$.

A contaminação de solos ${ }^{2}$ e rios ${ }^{3-5}$ por metais em áreas industrializadas é notória. Os efeitos adversos dos metais pesados são inseparavelmente relacionados à capacidade do solo de adsorver tais metais ${ }^{6}$. A turfa de ocorrência natural, a qual é bem decomposta e relativamente rica em húmus, é mais efetiva no fenômeno de adsorção de metais do que a disponível no comércio, que é rica em celulose, contendo cerca de $20 \%$ de ácidos húmicos?

As substâncias húmicas são na verdade, consideradas excelentes concentradores para uma grande variedade de elementos metálicos ${ }^{8}$. Rashid ${ }^{7}$ observou que cada $\mathrm{kg}$ da turfa por êle estudada foi capaz de adsorver cerca de $1500 \mathrm{mg}$ de metais em solução. A ordem observada de adsorção foi $\mathrm{Cu}>\mathrm{Ni}>\mathrm{Co}>$ $\mathrm{Zn}>\mathrm{Mn}$, sendo que na presença desses metais, o cobre foi preferencialmente adsorvido, utilizando cerca de $50 \%$ da capacidade total de adsorção da turfa. Estudos mais recentes têm sido conduzidos com a finalidade de avaliar a capacidade máxima de adsorção de turfas, através da construção de isotermas de adsorção. Neste caso, vários metais têm sido examinados, incluindo $\mathrm{Cu}, \mathrm{Cd}$ e $\mathrm{Zn}^{9}$ e $\mathrm{Cu}, \mathrm{Cd}, \mathrm{Co}, \mathrm{Ni}$ e $\mathrm{Zn}^{10}$. A habilidade de remoção de metais, de soluções aquosas ${ }^{11}$ e de águas residuais ${ }^{12}$ por turfa, têm demostrado resultados promissores para a sua aplicação como agente de despoluição.
Com base nos fatos descritos, o presente trabalho tem como objetivo promover a caracterização química e física de turfa litorânea, bem como avaliar a adsorção competitiva dos metais cobre e zinco por seus sítios ativos. Os resultados obtidos, que apontam as condições ideais, como tempo de retenção, competitividade em presença de outro metal, $\mathrm{pH}$ e concentração, poderão servir de base para estudos posteriores, visando a construção de filtros para a retenção dos metais estudados, a serem utilizados em processos de despoluição ambiental.

As caracteristicas da turfa examinada incluem, entre outras, a determinação do $\mathrm{pH}$, teor de matéria orgânica e análises elementar e de raios $\mathrm{X}$.

\section{MATERIAL E MÉTODOS}

\section{Coleta e tratamento inicial da amostra}

A amostra de turfa litorânea foi coletada em Arraial do Cabo, na Região dos Lagos, RJ, em três profundidades (20, 50 e $70 \mathrm{~cm}$ ), existindo em sua superfície uma salineira. As amostras foram recolhidas em tubo cilíndrico de PVC, sendo o material disposto em sacos plásticos resistentes e lacrados para não perder umidade. As amostras foram, então, armazenadas em refrigerador a $4{ }^{\circ} \mathrm{C}$ para posterior uso. Depois de seca ao ar, a amostra foi passada em peneira de 80 mesh.

\section{Caracterização de turfa litorânea}

\section{Matéria orgânica}

O teor de matéria orgânica foi determinado por combustão da amostra, em mufla, a $550{ }^{\circ} \mathrm{C}$, durante 24 horas ${ }^{1}$.

\section{Hidrogênio trocável}

Transferiram-se $100 \mathrm{mg}$ de amostra para um erlenmeyer de $250 \mathrm{~mL}$, juntamente com $100 \mathrm{~mL}$ de solução de $\mathrm{HCl} 0,1 \mathrm{~mol}$ $\mathrm{L}^{-1}$. Após filtrar a mistura através de papel de filtro Whatman 541 , adicionaram-se ao resíduo $50 \mathrm{~mL}$ de solução de $\mathrm{KCl} 1,0$ mol L ${ }^{-1}$. Após filtrar novamente, uma solução de $\mathrm{NaOH} 0,01$ mol $\mathrm{L}^{-1}$ foi utilizada para a titulação ${ }^{13}$. 


\section{Acidez total}

A acidez total (carboxila + hidroxila fenólica e enólica) foi determinada em $50 \mathrm{mg}$ de amostra, que foi previamente colocada em um frasco Erlenmeyer de $125 \mathrm{~mL}$ de capacidade com tampa de vidro sinterizado, e no qual adicionaram-se $20 \mathrm{~mL}$ de solução de hidróxido de bário $0,125 \mathrm{~mol} \mathrm{~L}^{-1}$. Ao mesmo tempo, preparou-se um branco consistindo somente da solução de bário. $\mathrm{O}$ ar foi retirado de cada frasco pela passagem de $\mathrm{N}_{2}$, sendo em seguida vedado com tampa e então agitado por $24 \mathrm{~h}$ em agitador magnético a temperatura ambiente $\left(20 \pm 2{ }^{\circ} \mathrm{C}\right)$. Após a etapa de filtração através de papel de filtro Whatman 541 , o filtrado obtido foi lavado com água destilada isenta de gás carbônico. A titulação potenciométrica foi, então, feita no filtrado contendo a água de lavagem até pH 8,4 com solução $0,5 \mathrm{~mol} \mathrm{~L}^{-1}$ de ácido clorídrico ${ }^{14}$.

\section{Grupos Carboxílicos}

Transferiram-se $50 \mathrm{mg}$ de amostra para erlenmeyer de $125 \mathrm{~mL}$, juntamente com alíquota de $10 \mathrm{~mL}$ de solução de acetato de cálcio $0,05 \mathrm{~mol} \mathrm{~L}^{-1}$. Após filtrar a mistura em papel de filtro Whatman 541 , titulou-se potenciometricamente até pH 9,8 com solução $0,1 \mathrm{~mol} \mathrm{~L}^{-1}$ de hidróxido de sódio ${ }^{14}$

\section{$p H$}

A determinação do $\mathrm{pH}$ foi feita em suspensão turfa-solução contendo $10 \mathrm{~g}$ da turfa e $25 \mathrm{~mL}$ de água deionizada, após repouso por 1 hora e filtração em papel de filtro Whatman $541^{15}$.

\section{Composição elementar}

As porcentagens, em peso, dos elementos presentes na turfa (C, N, S e H) foram determinadas em analisador, utilizando detector de infravermelho para $\mathrm{C}$ e $\mathrm{H}$, condutividade térmica para $\mathrm{N}$ e combustão secundária para $\mathrm{S}$.

\section{Difração de raios $X$}

Obteve-se o difratograma da amostra por exposição aos raios $\mathrm{X}$ em ângulos de $2 \theta$, de 4 a $40^{\circ}$, utilizando um tubo de radiação $\mathrm{Cu}-\alpha(\lambda=1,5405 \AA)$, a $35 \mathrm{kV}$ e $20 \mathrm{~mA}^{16}$.

\section{Adsorção de cobre e zinco por sítios da turfa litorânea}

Efeito da quantidade do metal adicionado sobre sua concentração em solução

Transferiram-se alíquotas de $10 \mathrm{~mL}$ de suspensão de turfa (contendo $0,5 \mathrm{~g}$ de turfa em $1000 \mathrm{~mL}$ de água deionizada, em $\mathrm{pH} 4,0$ ), para tubos de centrífuga de $50 \mathrm{~mL}$, aos quais foram adicionados, de cada vez, ora $3 \mathrm{~mL}$, ora $6 \mathrm{~mL}$, ora $10 \mathrm{~mL}$ de solução $5 \times 10^{-4} \mathrm{~mol} \mathrm{~L}^{-1}$ de cobre ou zinco, na forma de nitratos. Ajustou-se o pH das suspensões para 5,5 com solução de $\mathrm{NaOH} 0,01 \mathrm{~mol} \mathrm{~L}^{-1}$. Completou-se o volume dos tubos para $30 \mathrm{~mL}$ com água deionizada. Após agitação durante 15 horas à temperatura ambiente $\left(20 \pm 2{ }^{\circ} \mathrm{C}\right)$, as suspensões foram centrifugadas a $3000 \mathrm{rpm}$ durante 30 minutos. Lavaram-se os resíduos três vezes com água deionizada, centrifugou-se cada resíduo novamente após cada lavagem e completou-se o volume a $50 \mathrm{~mL}$. Determinaram-se as concentrações de cobre e zinco nas soluções (adaptado da literatura ${ }^{17}$ ).

\section{Oxidação destrutiva}

Levou-se uma porção de $5 \mathrm{mg}$ de amostra a um tubo de centrífuga de polietileno. Adicionaram-se $10 \mathrm{~mL}$ de solução dos metais $\mathrm{Cu}$ e $\mathrm{Zn} 5 \times 10^{-4} \mathrm{~mol} \mathrm{~L}^{-1}$, na forma de nitratos, e solução de $\mathrm{NaOH} 0,01 \mathrm{~mol} \mathrm{~L}^{-1}$, até atingir $\mathrm{pH} 7,0$, separadamente. Agitou-se por 18 horas e filtrou-se em papel de filtro Whatman 541. Diluiu-se o filtrado a $100 \mathrm{~mL}$ e determinaramse as concentrações dos metais. Lavou-se o resíduo com solução de $\mathrm{HNO}_{3}$ a $1 \%$ (v/v). Adicionaram-se $5 \mathrm{~mL}$ de $\mathrm{H}_{2} \mathrm{O}_{2}$ a 30 $\%(\mathrm{~m} / \mathrm{v})$. Após filtração em papel de filtro Whatman 541, diluiu-se a solução a $50 \mathrm{~mL}$ com água deionizada e determinaram-se as concentrações dos metais (adaptado da literatura ${ }^{17}$ ).

Efeito do tempo de adsorção sobre a concentração de cobre e zinco em solução

Transferiram-se $10 \mathrm{~mL}$ de suspensão de turfa (contendo 0,5 g de turfa em $1000 \mathrm{~mL}$ de água deionizada, em $\mathrm{pH} 4,0$ ), para tubos de centrífuga de $50 \mathrm{~mL}$ e adicionaram-se $10 \mathrm{~mL}$ de solução $5 \times 10^{-4} \mathrm{~mol} \mathrm{~L}^{-1}$ de cobre ou zinco, na forma de nitratos. Ajustou-se o pH das suspensões para 7,0, com solução de $\mathrm{NaOH} 0,01 \mathrm{~mol} \mathrm{~L}^{-1}$. Promoveram-se agitações manuais dos tubos a intervalos de 2 horas, sendo que a cada 4 horas, uma das misturas era filtrada em papel de filtro Whatman 541, determinando-se, em seguida, a concentração dos metais nas soluções. O tempo máximo avaliado foi de 22 horas.

\section{Efeito do pH sobre a concentração de cobre e zinco em solução}

Transferiram-se alíquotas de $10 \mathrm{~mL}$ de suspensão da turfa (contendo $0,5 \mathrm{~g}$ de turfa em $1000 \mathrm{~mL}$ de água deionizada, em $\mathrm{pH} 4,0$ ), para tubos de centrífuga de $50 \mathrm{~mL}$ de capacidade. A esses volumes adicionaram-se, isoladamente e na forma de nitratos, $10 \mathrm{~mL}$ de solução $5 \times 10^{-4} \mathrm{~mol} \mathrm{~L}^{-1}$ de cobre ou zinco e volumes variáveis de $\mathrm{NaOH} 0,01 \mathrm{~mol} \mathrm{~L}^{-1}$, necessários ao ajuste de $\mathrm{pH}$ na faixa de 4,25 a 10,0. Após o ajuste de $\mathrm{pH}$, procedeu-se de forma semelhante ao ítem do efeito da quantidade do metal adicionado sobre sua concentração em solução, como descrito anteriormente, na continuação da confecção deste experimento (adaptado da literatura ${ }^{17,18}$ ).

Efeito da competição de cobre e zinco em solução por sítios ativos de adsorção da turfa

Nesta série de experimentos, avaliou-se a competitividade de íons metálicos pelos sítios de troca da turfa litorânea. Adicionaram-se, seguidamente, a $10 \mathrm{~mL}$ da suspensão de turfa (contendo $0,5 \mathrm{~g}$ de turfa em $1000 \mathrm{~mL}$ de água deionizada, em $\mathrm{pH} 4,0), 2,5 \mathrm{~mL}$ de soluções $2 \times 10^{-3} \mathrm{~mol} \mathrm{~L}^{-1}$ de cobre e zinco, na forma de nitratos, ajustando o $\mathrm{pH}$ da suspensão ao de adsorção máxima para cada metal, como obtido no ítem anterior. Procedeu-se de forma semelhante ao ítem do efeito da quantidade do metal adicionado sobre sua concentração em solução, como descrito anteriormente, na continuação da confecção deste experimento (adaptado da literatura ${ }^{17-19}$ ).

\section{Aparelhagem e determinações}

A análise elementar foi efetuada no analisador de C, H, S e N, modelo 785-600, e na balança Leco-250, modelo 9751-300. Para leituras de pH foi utilizado potenciômetro da Tecnow, modelo IRIS 7, digital, equipado com eletrodos combinados de vidro (indicador) e prata-cloreto de prata (referência). As concentrações de $\mathrm{Cu}$ e $\mathrm{Zn}$ foram avaliadas em espectrofotômetro de absorção atômica Carl Zeiss Jena, modelo AAS3, equipado com corretor de absorção de fundo, por aspiração direta das soluções aquosas em chama ar-acetileno.

\section{Reagentes}

Todos os reagentes usados foram de grau analítico, de marca MERCK ou equivalente e ensaios em branco foram corridos em todos os experimentos para verificar qualquer contaminação. 


\section{RESULTADOS E DISCUSSÃO}

As substâncias húmicas compreendem em média, cerca de $40 \%$ da matéria orgânica dos sedimentos, atingindo em alguns casos, até $70 \%$. As turfas devem ter mais de $40 \%$ de matéria orgânica quando contendo $30 \%$ de água, ou mais de $60 \%$ de matéria orgânica, se calculada na base de material seco, a $110^{\circ} \mathrm{C}$. $\mathrm{O}$ valor encontrado nos testes laboratoriais para a profundidade amostrada de $20 \mathrm{~cm}, 76,4 \pm 0,2$ (Tabela 1), está de acordo com o previsto na literatura ${ }^{1}$, cujos valores mínimo, médio e máximo, com base no material seco são, respectivamente, 30,77 e $95 \%$.

Tabela 1. Características físicas e químicas de turfa litorânea ${ }^{a}$.

\begin{tabular}{|c|c|c|c|}
\hline \multirow[t]{2}{*}{ Componente } & \multicolumn{3}{|c|}{ Profundidade $(\mathrm{cm})$} \\
\hline & 20 & 50 & 70 \\
\hline $\begin{array}{l}\text { Matéria orgânica } \\
(\%, \mathrm{p} / \mathrm{p})\end{array}$ & $76,4 \pm 0,2$ & $65,7 \pm 0,2$ & $6,8 \pm 0,1$ \\
\hline $\mathrm{pH}$ & $4,5 \pm 0,1$ & $4,4 \pm 0,1$ & $4,6 \pm 0,1$ \\
\hline $\begin{array}{l}\text { Hidrogênio trocável } \\
\left(\mathrm{cmol}_{\mathrm{c}} \mathrm{dm}^{-3}\right)\end{array}$ & $14,1 \pm 0,1$ & $2,0 \pm 0,1$ & $9,0 \pm 0,1$ \\
\hline $\begin{array}{l}\text { Acidez total } \\
\left(\mathrm{cmol}_{\mathrm{c}} \mathrm{dm}^{-3}\right)\end{array}$ & $173,0 \pm 0,9$ & $178,0 \pm 1,0$ & $171,0 \pm 1$ \\
\hline $\begin{array}{l}\text { Grupos carboxílicos } \\
\left(\mathrm{cmol}_{\mathrm{c}} \mathrm{dm}^{-3}\right)\end{array}$ & $4,5 \pm 0,2$ & $4,4 \pm 0,1$ & $4,6 \pm 0,1$ \\
\hline
\end{tabular}

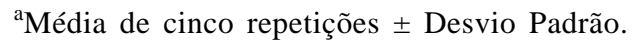

As faixas de $\mathrm{pH}$ que caracterizam as turfas variam entre 3,6-4,2 (muito ácida), 4,2-5,0 (ácida), 5,0-7,0 (baixa acidez), e acima de 7,9 (alcalina). As turfas têm normalmente $\mathrm{pH}$ baixo, graças ao suco celular das plantas que as originam, cuja reação é ácida ${ }^{1}$. No caso da turfa examinada neste trabalho, o $\mathrm{pH}$ médio, de acordo com a profundidade, foi 4,5 $\pm 0,1$ (Tabela 1). Em solos que apresentam baixos valores de $\mathrm{pH}$ (em torno de 4), as substâncias húmicas saturadas com hidrogênio apresentam muitas propriedades de polímeros neutros, tendo grande quantidade de ligações de hidrogênio. Com aumento do pH, os grupamentos ácidos das substâncias húmicas dissociam-se, e as macromoléculas orgânicas assumem as propriedades dos polieletrólitos. Os colóides orgânicos possuem áreas de exposição específicas duas a dez vezes maiores do que os colóides de solos minerais. As cargas negativas dos colóides orgânicos são dependentes do $\mathrm{pH}$, além de serem muito reduzidas sob condições ácidas do $\operatorname{solo}^{20}$. A populacão de elétrons "d" do íon metálico exerce um papel importante na interação desses íons com a turfa, assim como a sua carga ${ }^{8}$.

Pode-se afirmar que depois da capacidade de absorver água, as duas principais propriedades da turfa são a capacidade de troca catiônica (CTC) e o poder tampão. A turfa fornece ao solo maior poder tampão, o que impede variações bruscas de $\mathrm{pH}$, prejudiciais aos microrganismos e às raízes das plantas ${ }^{1}$.

Os valores de acidez total e grupos carboxílicos, determinados para a turfa coletada em diferentes profundidades, são mostrados na Tabela 1, sendo expressos em $\mathrm{cmol}_{\mathrm{c}} \mathrm{dm}^{-3}$ (centimol de carga por decímetro cúbico, ou meg $100 \mathrm{~cm}^{-3}$ ). Todos os ácidos húmicos são altamente aromáticos e contém grupos hidroxilfenólicos como grupos funcionais dominantes. Eles são relativamente ricos em radicais livres, devido principalmente àqueles de natureza semiquinona. Pelos valores observados para grupos $\mathrm{COOH}$, que estão de acordo com os encontrados na literatura ${ }^{21}$, pode-se atribuir à alta acidez total $(\mathrm{COOH}$ e $\mathrm{OH}$ fenólicos $)$ principalmente aos grupos hidroxil-fenólicos. Como a amostra de turfa é um material heterogêneo, coletada sob a influência de uma salineira, a mesma pode conter elevado teor de lignina e material proveniente de lignina. Assim, devido ao reduzido processo de humificação, os derivados de lignina provenientes de compostos fenólicos pouco alterados, influenciam em grande parte a acidez. A acidez total sugere elevada capacidade de troca catiônica e reatividade química ${ }^{22}$.

Ácidos húmicos e fúlvicos extraídos de solos orgânicos também podem apresentar valores de grupos OH fenólicos superiores aos de grupos $\mathrm{COOH}^{23}$.

Os valores de hidrogênio trocável encontram-se na Tabela 1. $\mathrm{Na}$ profundidade de $50 \mathrm{~cm}$ o valor está abaixo do encontrado na literatura ${ }^{8}$, isto é, $2,5 \mathrm{cmol}_{\mathrm{c}} \mathrm{dm}^{-3}$. Por outro lado, para as profundidades de 20 e $70 \mathrm{~cm}$, os valores são mais elevados, não encontrando-se até o momento explicação plausível para este fato.

As porcentagens de carbono, enxofre, hidrogênio e nitrogênio (Tabela 2) estão de acordo com os relatados para estes materias $1,14,20,24$. São evidentes as elevadas quantidades de nitrogênio e matéria orgânica nos solos orgânicos. Estes solos mostram alta relação $\mathrm{C} / \mathrm{N}$ (em que o quociente mínimo se apresenta na vizinhança de 20), e a despeito deste elevado valor, apresentam via de regra, excessiva nitrificação. Assim, o acúmulo de nitratos é, em geral, maior do que o de um solo mineral representativo ${ }^{14}$. Já o nitrogênio na forma de amônia é encontrado em pequena quantidade, por ser produzido pela decomposição da matéria orgânica, não se acumulando, no entanto, por ser consumido pelas plantas e pelos próprios microrganismos que decompõem os carboidratos dos tecidos vegetais. Nas turfeiras drenadas, a amônia pode oxidar-se a nitrato, forma química mais estável. O nitrogênio nesse material fóssil provém unicamente das plantas que originaram a turfeira. O enxofre, por sua vez, está presente no solo na forma mineral ou orgânica, constituindo-se esta, de 50 a $70 \%$ do total. Embora o enxofre seja um micronutriente secundário, é extraído do solo em grandes quantidades pelas plantas ${ }^{1}$.

Tabela 2. Análise elementar e relação atômica $\mathrm{C} / \mathrm{N}, \mathrm{H} / \mathrm{C}$ e N/ $\mathrm{S}$ de turfa litorânea.

\begin{tabular}{lccc}
\hline & \multicolumn{3}{c}{ Profundidade $(\mathrm{cm})$} \\
Determinação & 20 & 50 & 70 \\
& \multicolumn{3}{c}{ Porcentagem em peso } \\
Carbono & 35,1 & 30,6 & 19,2 \\
Enxofre & 1,0 & 0,8 & 0,2 \\
Hidrogênio & 4,6 & 3,6 & 2,5 \\
Nitrogênio & 0,6 & 0,3 & 0,1 \\
& \multicolumn{3}{c}{ Relação atômica } \\
Relação C/N & 69,5 & 102,0 & 177,0 \\
Relação H/C & 1,6 & 1,4 & 1,5 \\
Relação N/S & 1,3 & 1,0 & 1,5 \\
\hline
\end{tabular}

$\mathrm{O}$ exame de raios $\mathrm{X}$ da turfa litorânea detectou a presença somente de halita $(\mathrm{NaCl})$ e quartzo (Figura 1). Este resultado era previsto pois a turfa encontra-se em uma região de salineira, o que justifica a presença deste sal na amostra. A ausência de outros minerais, além dos encontrados, é uma indicação da pureza relativa da turfa coletada.

Quanto ao efeito da concentração inicial sobre a porcentagem adsorvida de cobre e zinco, em solução, na presença de turfa litorânea amostrada a 20, 50 e $70 \mathrm{~cm}$, em pH arbritariamente escolhido $(5,5)$, ficou evidenciado que os íons $\mathrm{Zn}^{2+}$ foram consideravelmente removidos (entre 51,7 $\pm 0,1$ e $65,1 \pm 0,6 \%$ ) de suas soluções (Tabela 3 ). $\mathrm{O}$ pH examinado para o zinco foi o mesmo em que ocorre sua adsorção máxima. Por outro lado, a faixa de porcentagem de adsorção dos íons $\mathrm{Cu}^{2+}$ variou entre $50,7 \pm 0,1$ e $57,1 \pm 0,3 \%$.

Evidenciou-se ainda, pelo exame da Tabela 3, que para todas as profundidades examinadas, as porcentagens de retenção dos metais elevaram-se de acordo com o aumento da concentração inicial do metal. Enquanto que a variação da concentração do cobre em função da profundidade foi relativamente 


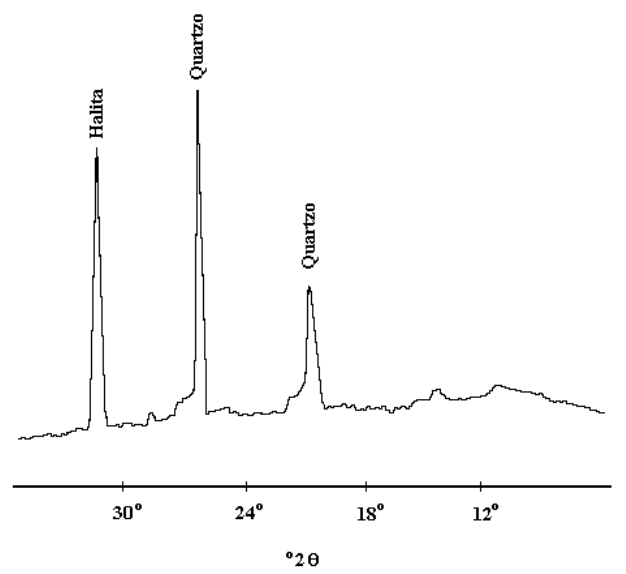

Figura 1. Difratograma (Raios X) de turfa litorânea.

Tabela 3. Efeito da concentração inicial, em porcentagem adsorvida, sobre as concentrações de $\mathrm{Cu}$ e $\mathrm{Zn}$ em solução, na presença de turfa litorânea, em pH 5,5.

\begin{tabular}{|c|c|c|c|c|}
\hline \multirow{3}{*}{ Metal } & \multirow{3}{*}{$\begin{array}{l}\text { Profundidade } \\
\qquad(\mathrm{cm})\end{array}$} & \multicolumn{3}{|c|}{ Concentração inicial $\left(\mathrm{mol} \mathrm{L}^{-1} \times 10^{-5}\right)$} \\
\hline & & 5,0 & 10,0 & 16,7 \\
\hline & & \multicolumn{3}{|c|}{ Porcentagem $\pm \mathrm{DP}^{\mathrm{a}}$} \\
\hline \multirow[t]{3}{*}{$\mathrm{Cu}$} & 20 & $51,4 \pm 0,6$ & $52,7 \pm 0,1$ & $54,4 \pm 0,2$ \\
\hline & 50 & $53,1 \pm 0,4$ & $56,4 \pm 0,2$ & $57,1 \pm 0,3$ \\
\hline & 70 & $50,7 \pm 0,1$ & $51,3 \pm 0,3$ & $52,6 \pm 0,1$ \\
\hline \multirow[t]{3}{*}{$\mathrm{Zn}$} & 20 & $63,9 \pm 0,3$ & $64,6 \pm 0,6$ & $65,1 \pm 0,6$ \\
\hline & 50 & $61,7 \pm 0,1$ & $63,1 \pm 0,3$ & $64,2 \pm 0,8$ \\
\hline & 70 & $51,7 \pm 0,1$ & $52,1 \pm 0,2$ & $55,3 \pm 0,5$ \\
\hline
\end{tabular}

${ }^{\mathrm{a}}$ Média de cinco repetições \pm Desvio Padrão.

pequena, no caso do zinco, ocorreu diminuição de suas concentrações a medida em que se coletou as amostras de turfa mais profundas. Pode-se atribuir as maiores concentrações de zinco, nas camadas mais superficiais da turfa, as maiores porcentagens de matéria orgânica nestas camadas. Por outro lado, as pequenas variações das concentrações de cobre, em função da profundidade examinada, pode ser devida a maior afinidade deste elemento pela matéria orgânica ${ }^{25}$.

A matéria orgânica de solos e sedimentos geralmente é oxidada com água oxigenada para determinação de micronutrientes $^{26}$. As recuperações de cobre e zinco, após a oxidação da turfa, a qual foi previamente submetida à adsorção desses metais, estão apresentadas na Tabela 4. Esta oxidação foi realizada com o objetivo de comprovar a retenção do metal pela turfa. No entanto, verifica-se a não totalização de $100 \%$. Enquanto que a porcentagem de zinco extraída variou entre $83,0 \pm 0,1$ e $89,0 \pm$ $0,1 \%$, a de cobre ficou entre $90,0 \pm 0,1$ e $94,0 \pm 0,6 \%$. Alguns problemas de natureza analítica podem surgir como resultado do uso de água oxigenada como oxidante da matéria orgânica. Apesar da eficiência deste oxidante em romper ligações entre os metais e a matéria orgânica dos quelatos, nem todas as formas de matéria orgânica são necessariamente oxidadas ${ }^{27}$.

Neste estudo, foi conduzido um procedimento para determinar o efeito do tempo na adsorção de cobre e zinco pela turfa (Figura 2 e 3). Para as profundidades amostradas $(20,50$ e 70 $\mathrm{cm})$, as porcentagens de retenção do cobre não variaram significativamente entre 8 e 20 horas, apresentando-se os gráficos de adsorção x tempo em formatos semelhantes. Quanto ao zinco, observa-se que o tempo de adsorção máximo foi de 18 horas.

Estudos sobre o comportamento de íons metálicos com materiais ricos em matéria orgânica têm demonstrado que não há precipitação mensurável de ácidos húmicos, ferro, manganês,
Tabela 4. Porcentagem extraída de $\mathrm{Cu}$ e $\mathrm{Zn}$ de turfa litorânea, após oxidação destrutiva (concentração do íon metálico antes da oxidação, $\left.5 \times 10^{-4} \mathrm{~mol} \mathrm{~L}^{-1}\right)$.

\begin{tabular}{lcc}
\hline Metal & Profundidade $(\mathrm{cm})$ & Porcentagem extraída $\pm \mathrm{DP}^{\mathrm{a}}$ \\
\hline $\mathrm{Cu}$ & 20 & $94,0 \pm 0,6$ \\
& 50 & $94,0 \pm 0,1$ \\
$\mathrm{Zn}$ & 70 & $90,0 \pm 0,1$ \\
& 20 & $89,0 \pm 0,1$ \\
& 50 & $84,0 \pm 0,1$ \\
& 70 & $83,0 \pm 0,1$ \\
\hline
\end{tabular}

${ }^{\mathrm{a}}$ Média de cinco repetições \pm Desvio Padrão.

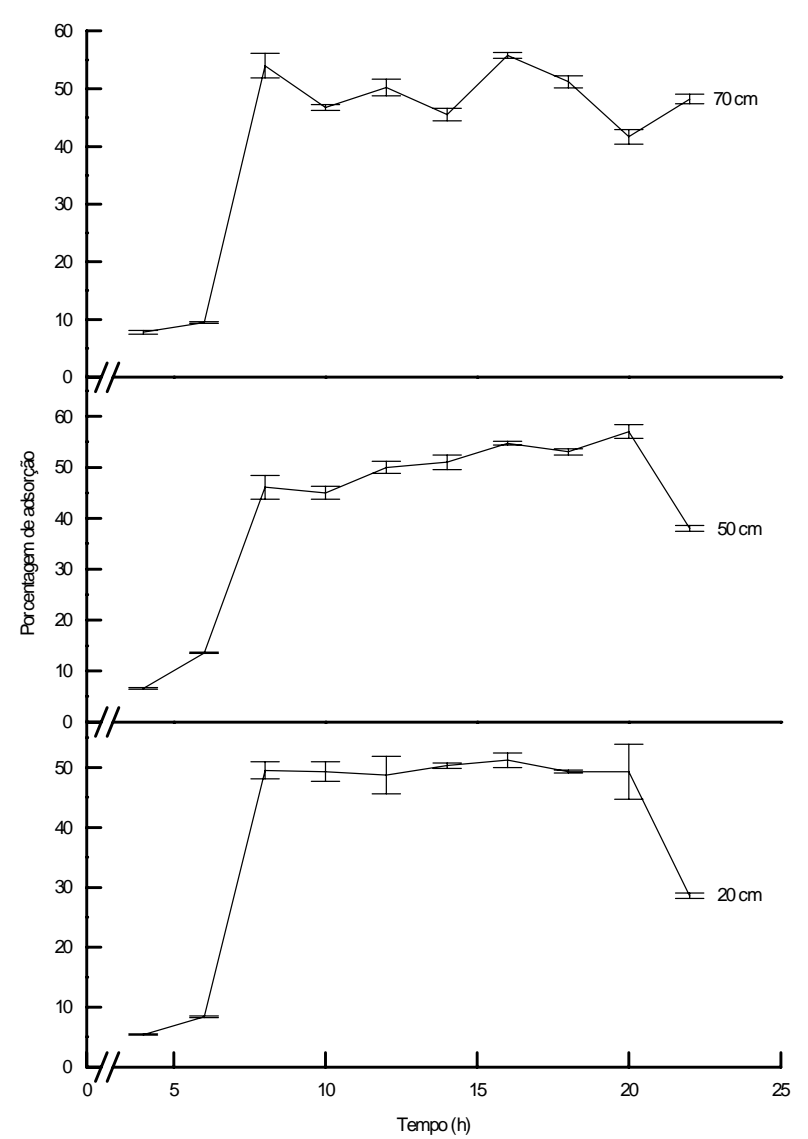

Figura 2. Efeito do tempo sobre a adsorção de cobre em turfa litorânea.

cobre, níquel, cádmio ou cobalto, quando o $\mathrm{pH}$ se eleva acima de 6,5 , indicando que os metais são mantidos na fase dissolvida em concentrações muito elevadas ${ }^{8}$. No caso do íon $\mathrm{Cu}^{2+}$, em $\mathrm{pH}$ 9,0 , ocorreram os maiores valores de adsorção, para as três profundidades examinadas (Figura 4). As concentrações a esses níveis elevados de $\mathrm{pH}$ podem ser controladas pelo $\mathrm{Cu}$ organicamente complexado, talvez, ainda, com concentrações de $\mathrm{Cu}$ livre, em equilíbrio com hidróxido de cobre ${ }^{28}$. A adsorção máxima de $\mathrm{Zn}$ ocorreu em $\mathrm{pH}$ 5,5 para as três profundidades examinadas (Figura 5). Em pH mais elevado, como por exemplo 8,0, pode ocorrer a precipitação de zinco, e em $\mathrm{pH}$ mais baixo, pode ocorrer redução de adsorção do $\mathrm{Zn}$ para solos arenosos, mais do que naqueles solos ricos em material coloidal ${ }^{29}$.

A extensão da adsorção em um dado $\mathrm{pH}$ varia grandemente entre metais, embora cátions metálicos de transição bivalentes exibam adsorção similar dependente do $\mathrm{pH}$. Para adsorção por subsolos ácidos das Planícies da Costa Atlântica, similares ao do presente trabalho, obteve-se a seguinte sequência a $\mathrm{pH} 5,0: \mathrm{Cu}>$ $\mathrm{Zn}$, a partir do mesmo nível inicial de metais em solução ${ }^{30}$. No 


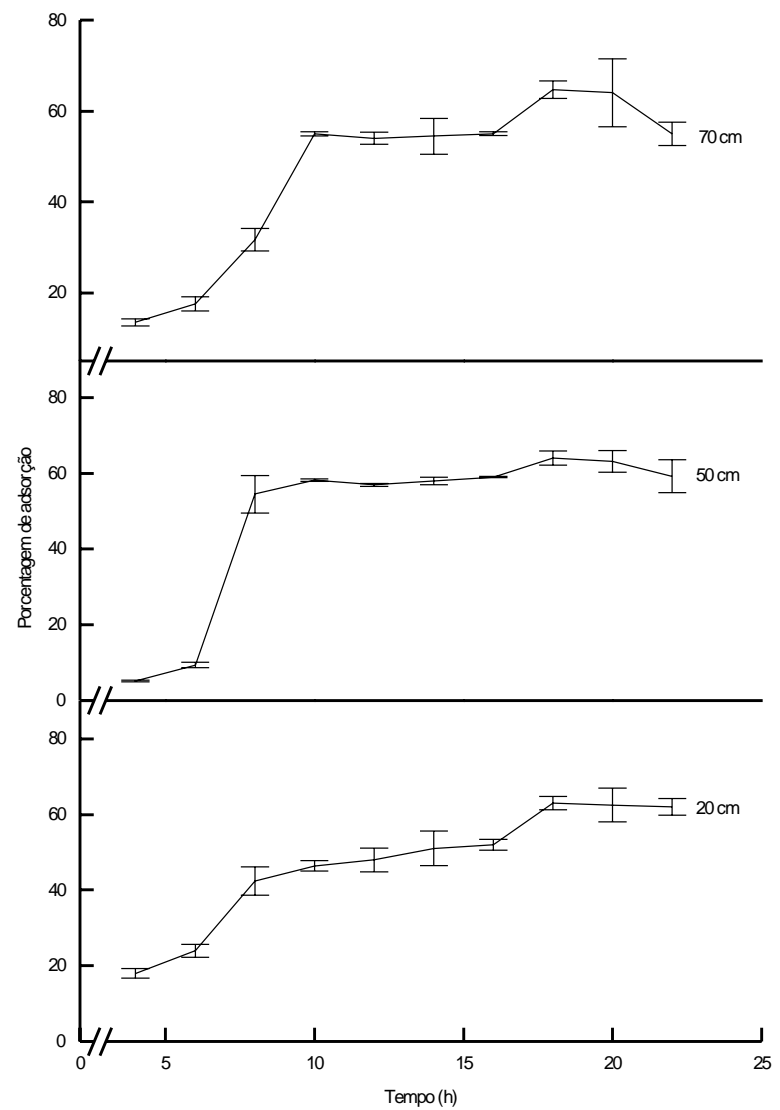

Figura 3. Efeito do tempo sobre a adsorção de zinco em turfa litorânea.

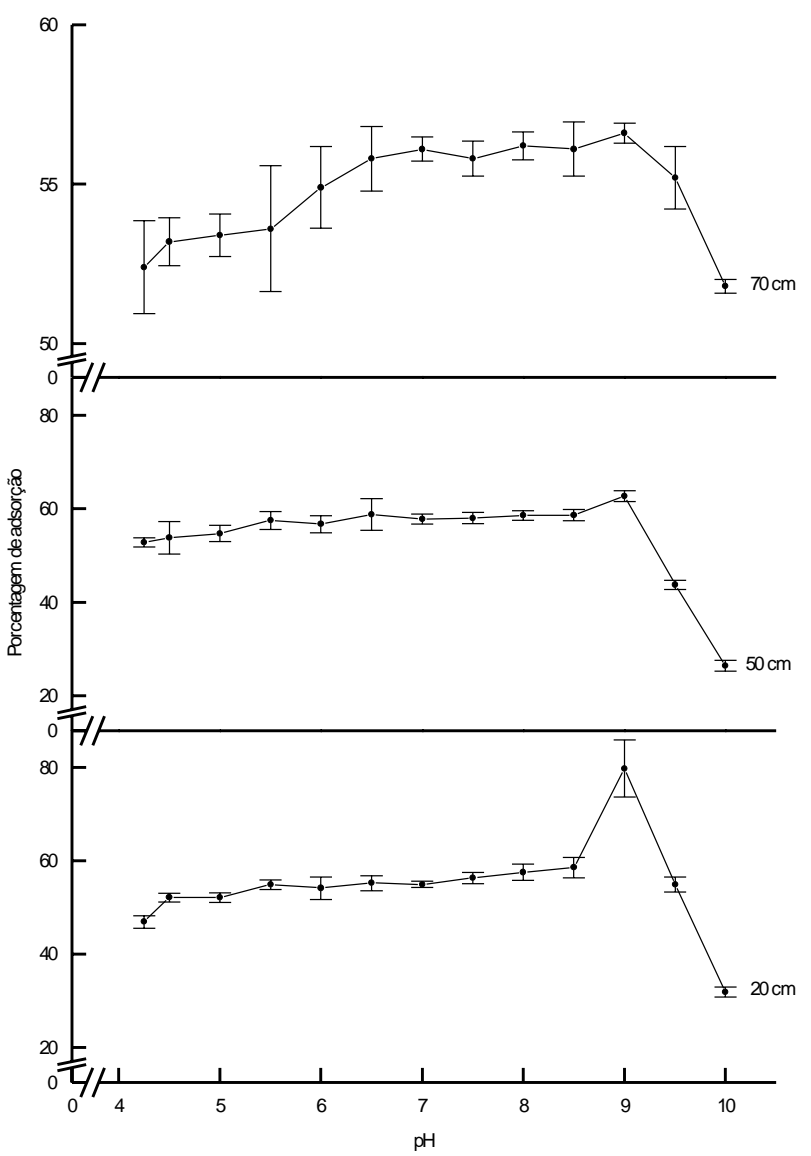

Figura 4. Efeito do pH sobre a adsorção de cobre em turfa litorânea.

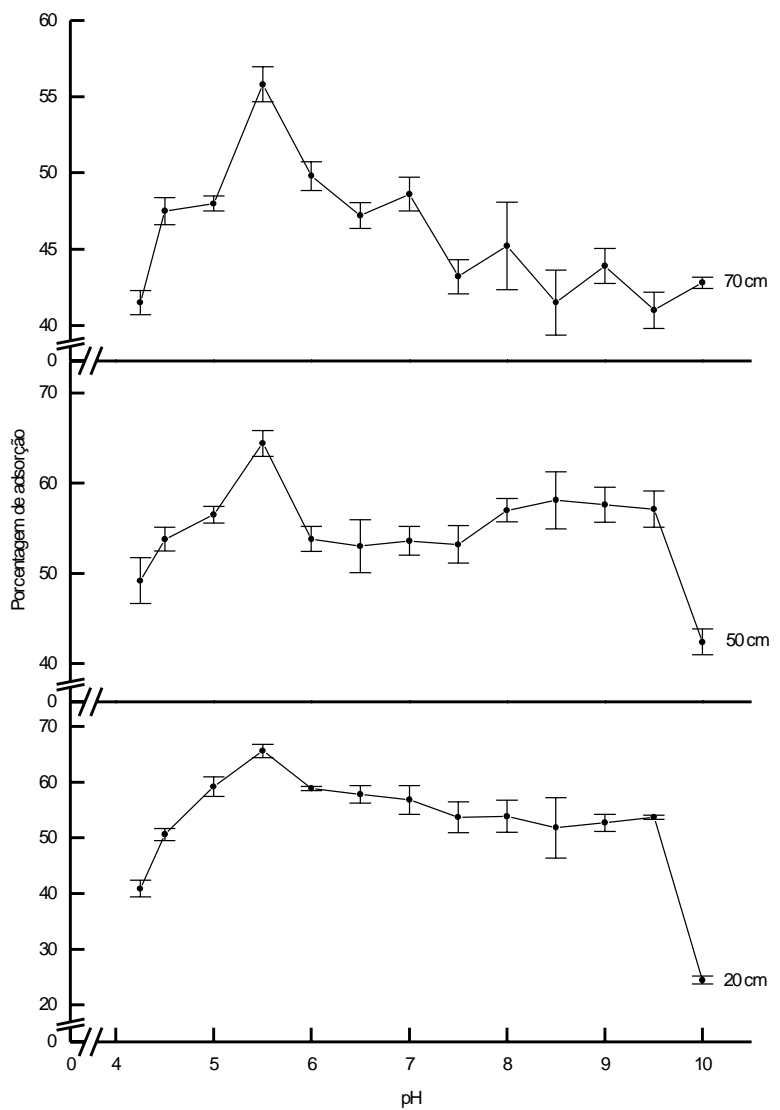

Figura 5. Efeito do pH sobre a adsorção de zinco em turfa litorânea.

presente trabalho, a ordem foi $\mathrm{Zn} \cong \mathrm{Cu}$. A validade desta série de disponibilidade para a maioria dos solos é questionável, não obstante a série de tipos e quantidades de argilas, óxidos e matéria orgânica encontrados nos solos. Cada constituinte do solo tem suas próprias propriedades de se ligar a metais, resultando, em conseqüência, em diferentes graus de adsorção. Vários pesquisadores expressaram a força de ligação das interações metal-matéria orgânica do solo em termos de constante de estabilidade entre íons metálicos e matéria orgânica extraída do solo. A força de ligação relativa depende da natureza da matéria orgânica, em função do $\mathrm{pH}^{30}$.

A formação de mais de uma ligação entre o metal e a molécula orgânica usualmente fornece alta estabilidade ao complexo. Em certas circunstâncias, a concentração do íon metálico pode ser reduzida a um nível não tóxico através da complexação. Isto pode ser particularmente verdadeiro quando o complexo metálico tem baixa solubilidade, tal qual o caso com complexos de ácidos húmicos e outros componentes de alta massa molar de matéria orgânica ${ }^{14}$.

Os horizontes carbonados, altamente tamponados, fixam cerca de $99 \%$ dos metais pesados na camada de 10 a $20 \mathrm{~cm}$. Em solos fracamente ácidos, os metais podem migrar a uma profundidade de $40 \mathrm{~cm}$, e em solos pobremente tamponados, os metais pesados podem ser encontrados até 60 ou $80 \mathrm{~cm}$ de profundidade, mas a maior parte é adsorvida na camada de 0 a $10 \mathrm{~cm}$ em solos virgens, ou de 10 a $20 \mathrm{~cm}$ em solos arados ${ }^{31}$. Geralmente, em menores valores de $\mathrm{pH}$, sua capacidade de adsorção é aumentada, sendo a eficiência do processo normalmente alta para altas concentrações ${ }^{32}$.

Enquanto que cátions monovalentes $\left(\mathrm{Na}^{+}, \mathrm{K}^{+}\right.$, etc.) são mantidos primariamente por simples troca, por meio da formação de sais com grupos - $\mathrm{COOH}$ (RCOONa; RCOOK), os cátions multivalentes $\left(\mathrm{Cu}^{2+}, \mathrm{Zn}^{2+}, \mathrm{Mn}^{2+}, \mathrm{Co}^{2+} \mathrm{e}\right.$ outros $)$ possuem potencial para formar ligações com moléculas orgânicas ${ }^{14}$. 
A estabilidade do complexo metal-quelato é determinada por uma variedade de fatores, incluindo o número de átomos que formam uma ligação com o íon metálico, o número de anéis que são formados, a natureza e concentração do íon metálico e o pH. A sequência de estabilidade para alguns cátions divalentes segue a ordem: $\mathrm{Cu}^{2+}>\mathrm{Ni}^{2+}>\mathrm{Co}^{2+}>\mathrm{Zn}^{2+}>\mathrm{Fe}^{2+}>\mathrm{Mn}^{2+}$.

Os ácidos húmicos isolados de sedimentos marítimos são efetivos na adsorção de vários íons metálicos, através da quelatação, troca catiônica e superfície de adsorção. O ambiente sedimentário é um meio complexo, onde uma grande variedade de cátions polivalentes existem em várias concentrações, sendo que estes competem uns com os outros na quelatação e reação de adsorção. O mecanismo químico mais adequado para reação de matéria húmica com íons metálicos é a quelatação, na qual o íon metálico está firmemente ligado às moléculas orgânicas. As reações de troca catiônica simples são também importantes no fenômeno de adsorção metálica. Em vista da natureza coloidal de compostos húmicos, a adsorção física de íons metálicos na superfície coloidal de moléculas orgânicas pode ser também um importante mecanismo de retenção metálica ${ }^{7}$.

Há poucas publicações referentes ao comportamento de turfas na adsorção competitiva de metais. Por esse motivo, os resultados obtidos no presente trabalho devem ser julgados, por falta de parâmetros, de modo empírico. A capacidade de retenção dos íons $\mathrm{Cu}^{2+}$ e $\mathrm{Zn}^{2+}$ pela turfa litorânea variou de acordo com o pH e com o metal, isolado ou em mistura (Tabela 5). Em geral, observou-se uma tendência de menor adsorção do zinco com o incremento da profundidade, quando examinado no respectivo valor de $\mathrm{pH}$ de adsorção máxima, isto é, a pH 5,5. Verificou-se, ainda, que ao se fazerem as combinações possíveis de cobre e zinco nos valores de $\mathrm{pH}$ de adsorção máxima, ocorreu competição entre os cátions metálicos pelos sítios de adsorção das turfas.

Tabela 5. Competição de $\mathrm{Cu}$ e $\mathrm{Zn}$, em porcentagem adsorvida, por sítios de ligação de turfa litorânea, em valores de $\mathrm{pH}$ de adsorção máxima.

\begin{tabular}{|c|c|c|c|c|}
\hline \multirow{3}{*}{$\begin{array}{l}\text { Profundidade } \\
\text { (cm) }\end{array}$} & \multicolumn{4}{|c|}{ Porcentagem de adsorção $\pm \mathrm{DP}^{\mathrm{a}}$} \\
\hline & & $9,0^{\mathrm{b}}$ & $\mathrm{pH}$ & $5,5^{\mathrm{c}}$ \\
\hline & $\mathrm{Cu}$ & $\mathrm{Cu}+\mathrm{Zn}^{\mathrm{d}}$ & $\mathrm{Zn}$ & $\mathrm{Zn}+\mathrm{Cu}^{\mathrm{e}}$ \\
\hline 20 & $79,7 \pm 3,6$ & $43,8 \pm 3,7$ & $65,5 \pm 0,8$ & $22,0 \pm 0,3$ \\
\hline 50 & $79,7 \pm 1,5$ & $38,5 \pm 2,5$ & $64,4 \pm 3,2$ & $20,2 \pm 0,4$ \\
\hline 70 & $56,6 \pm 0,5$ & $41,3 \pm 1,1$ & $56,0 \pm 1,1$ & $19,0 \pm 0,4$ \\
\hline
\end{tabular}

${ }^{a}$ Média de cinco repetições \pm Desvio Padrão. ${ }^{b} \mathrm{pH}$ de adsorção máxima do cobre. ${ }^{\mathrm{c}} \mathrm{pH}$ de adsorção máxima do zinco. ${ }^{\mathrm{d}} \mathrm{Cu}$ seguido por $\mathrm{Zn}$. ${ }^{\mathrm{Z}} \mathrm{Zn}$ seguido por $\mathrm{Cu}$.

Observou-se uma forte influência do íon $\mathrm{Zn}^{2+}$ na adsorção do íon $\mathrm{Cu}^{2+}$, ao $\mathrm{pH}$ de adsorção selecionado para este elemento $(\mathrm{pH} 9,0)$. Para a amostra de turfa coletada a $50 \mathrm{~cm}$ de profundidade, a presença de íons $\mathrm{Zn}^{2+}$ reduziu a adsorção em torno de $52 \%$. Nas amostras de turfa coletadas nas profundidades de $20 \mathrm{~cm}$ e $70 \mathrm{~cm}$, a influência de metal competidor também foi pronunciada, reduzindo semelhantemente a adsorção (45\% e $27 \%$, respectivamente). No valor de $\mathrm{pH}$ de adsorção máxima do zinco (pH 5,5), a presença do íon competidor $\mathrm{Cu}^{2+}$ afetou em torno de $66 \%$ a adsorção daquele elemento, considerando as adsorções nas turfas coletadas nas diversas profundidades examinadas.

\section{AGRADECIMENTO}

À CAPES pela concessão de uma bolsa a Agenor Paulo Binato Lamim no curso de Mestrado em Agroquímica do Departamento de Química da Universidade Federal de Viçosa.

\section{REFERÊNCIAS}

1. Kiehl, E. J.; Fertilizantes Orgânicos; Agronômica Ceres; São Paulo, 1985.

2. Jordão, C. P.; Pereira, J. C.; Brune, W.; Pereira, J. L.; Braathen, P. C.; Environ. Technol. 1996, 17, 489.

3. Jordão, C. P.; Pereira, J. L.; Jham, G. N.; Sci. Total Environ. 1997, 207, 1.

4. Jordão, C. P.; Pereira, J. L.; Jham, G. N.; Bellato, C. R.; Environ. Technol. 1999, 20, 489.

5. Jordão, C. P.; Silva, A. C.; Pereira, J. L.; Brune, W.; Quim. Nova 1999, 22, 47.

6. Alloway, B. J.; In Heavy Metals in Soils; Alloway, B. J., Ed.; Blackie Academic \& Professional; Glasgow, 1993.

7. Rashid, M. A.; Chem. Geol. 1974, 13, 115.

8. Andrade, W. O.; Tese de Doutorado; Pontifícia Universidade Católica do Rio de Janeiro; Rio de Janeiro, RJ, 1986.

9. McKay, G.; Porter, J. F.; Process. Saf. Environ. 1997, $75,171$.

10. McKay, G.; Vong, B.; Portet, J. F.; Adsorpt. Sci. Technol. 1998, $16,51$.

11. Ho, Y. S.; Wase, D. A. J.; Förstner, C. F.; Process Saf Environ. 1994, 72, 185.

12. Allen, S. J.; Murray, M.; Brown, P.; Flynn, O.; Resour Conserv. Recy. 1994, 11, 25.

13. Kamprath, E. J.; Welch, C. D.; Soil Sci. Amer. Proc. 1962, 26, 263.

14. Stevenson, F. J.; Humus Chemistry; John Wiley \& Sons, Inc.; New York, 1982.

15. Vettori, L; Métodos de Análise do Solo; Ministério da Agricultura (Boletim Técnico 7); Brasília, 1969.

16. Franco, I. A. L.; Dissertação de Mestrado; Universidade Federal de Viçosa; Viçosa, MG, 1991.

17. Siqueira, R. N. B.; Dissertação de Mestrado; Universidade Federal de Viçosa; Viçosa, MG, 1988.

18. Costa, E. D.; Quim. Nova 1993, 16, 517.

19. Jordão, C. P.; Siqueira, R. N. B.; Goulart, A. T.; Brune, W.; Ci. Cult. 1990, 42, 797.

20. Brady, N. C.; Natureza e Propriedades dos Solos; Freitas Bastos; Rio de Janeiro, 1989.

21. Prasad, B.; Sinha, M. K.; J. Indian Soc. Soil Sci. 1983, 31, 187.

22. Schnitzer, M.; Barr, M.; Hartenstein, R.; Soil Biol. Biochem. 1984, 16, 371.

23. Poppi, N. R.; Talamoni, J.; Quim. Nova 1992, 15, 281.

24. Flaig, W.; Beutelspacher, H.; Rietz, E.; Chemical Composition and Physical Properties of Humic Substances; J. E. Giebeking; New York, 1975.

25. Cavallaro, N.; McBride, M. B.; Soil Sci. Soc. Am. J. 1978, $42,550$.

26. Gupta, S. K.; Chen, K. Y.; Environ. Lett. 1975, 10, 129.

27. Himes, F. L.; Barber, S. A.; Soil Sci. Soc. Proc. 1957, 21, 368.

28. Kuo, S.; Baker, A. S.; Soil Sci. Soc. Am. J. 1980, 44, 969.

29. Shuman, L. M.; Soil Sci. Soc. Amer. Proc. 1975, 39, 454.

30. Elliott, H. A.; Liberati, M. R.; Huang, C. G.; J. Environ. Qual. 1986, 15, 214.

31. Sandovnikova, L. K.; Zyrin, N. G.; Soviet Soil Sci. 1986, 17, 58.

32. Neves, P. J.; Dissertação de Mestrado; Pontifícia Universidade Católica do Rio de Janeiro, Rio de Janeiro, RJ, 1980. 